\title{
Modelling and Simulation of Venturi Parameters in Relation to Geometries and Discharge Coefficient with Computational Fluid Dynamics Technique
}

\author{
Pushpak R. Shinde ${ }^{1}$ \\ ${ }^{1}$ M. Engg Student \\ Department of Automotive Engineering, \\ Ostfalia University of Applied Science, \\ Wolfsburg. Germany \\ Rahul H. Chaudhari ${ }^{2}$ \\ ${ }^{2}$ M.B.A and Engg Student \\ Department of Operational Excellence, \\ Hof University of Applied Science, \\ Hof, Germany
}

\author{
Prayag S. Patil ${ }^{3}$ \\ ${ }^{3}$ M.Tech Student \\ Department of Design and Automation, \\ Vellore Institute of Technology, \\ Vellore, India \\ Satish S. Marathe ${ }^{4}$ \\ ${ }^{4}$ M.Tech Student \\ Department of Automotive Engineering, \\ Vel Tech University, \\ Chennai, India
}

\begin{abstract}
Fluid flow characteristics include liquid, as well as gas, plays a vital role in the modern-day engineering field having extensive application in the industries. The investigation of fluid flow and its characteristics is essential to perform experimentation with engineering studies. Computation of flow rate through a pipe is done with the difference of pressure head available at the cross-section area of the pipe. The meter which performs the said computation of fluid flow termed as a venturimeter. Venturimeter finds useful in plumbing, fluid oil pipeline, automotive carburetor, petroleum chemical industries, etc. In this experimental study, an investigation is carried out in fluid engineering lab equipped with facility for flow calibration. Venturimeter and orifice meter are employed to measure discharge coefficients for the fluid considered in the experiment. The impact of angles on fluid characteristics is studied by modelling through computational fluid dynamics (CFD) approach. Fluid flow within venturimeter is simulated with a steady flow in k-epsilon model. The experimental model obtained with the beta ratio 0.6 together with inputs of three different angles for convergent as well as a divergent section of venturi. The respective angles are 21, 20, 21 and 9,11,7 for convergent and divergent side, respectively. Pre-processing of experimental model geometry was performed using CREO. In the processing phase, ANSYS tool was utilized for the meshing and definition of boundary conditions. Within post-processing, contours of pressure and velocity were determined with CFX solver. The experimental data was validated and compared with CFX result.
\end{abstract}

Keywords-ANSYS 14.0, Bernoulli's equation, CFD, coefficient of discharge

\section{INTRODUCTION}

The venturi meter is an obstruction meter named in honor of Giovanni Venturi (1746-1822), an Italian physicist who first tested conical expansions and contractions. The original, or classical, venturi was invented by a U.S. engineer, Clemens Herschel, in 1898. It consisted of a 21-degree conical contraction, a straight throat of diameter $d$ and length $d$, then 7 to 15-degree conical expansion [1]. The basic principle on which a venture meter work is that by reducing the crosssectional area of the flow passage, a pressure difference is created, and the measurement of this pressure difference enables the determination of discharge through a pipe. Nowadays, it is necessary to perform the calibration tests of the flow meters to find out the accuracy of the instrument. These can be done by calculating the discharge coefficient of the venturi. Although experimental procedures offer a good result, they are often time-consuming. Hence a more sophisticated method of testing the flow meter is through numerical methods.

Due to a variety of commercial CFD codes being available in the market, it is possible to obtain more accurate results which take less time. These results can then be compared with the initial experimental results to calibrate the instrument [1]. Pipes as fluid flows are widely used in piping systems in the industry, mining, and distribution of drinking water. The series of pipes are designed in such a way as to be able to meet the need for fluid distribution. Various types and angles of pipe branching in piping systems will produce different flow distributions. Measurement of flow flowing through the closed channel is done by using venturi meters. The conditions encountered in thick liquid metering can be beyond the scope of application for industry standards (ISO 5167-1) [2].

The venturi meters have convergent cone inlets, cylindrical necks, and divergent recovery cones. It has no projection to the liquid; there is no sharp angle and no sudden changes in the contour. The following Fig. 1 shows venturi meters with uniform cylindrical parts before converging, neck canal and divergent [3].

Due to convergent entrance speed of fluid flow increases and pressure decreases in the middle of cylinder neck pressure or speed will not change. Thus, the pressure difference corelates with the fluid flow rate using Bernoulli's equation. The total energy at each point of the fluid is constant; the 
total energy consists of pressure energy, kinetic energy, and potential energy.

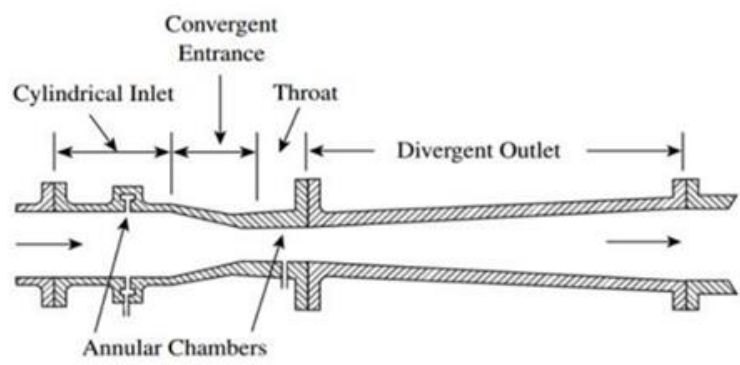

Fig. 1. A cross-sectional view of a venturi

$$
\frac{P_{1}}{\rho g}+\frac{V_{1}^{2}}{2 g}+z_{1}=\frac{P_{2}}{\rho g}+\frac{V_{2}^{2}}{2 g}+z_{2}
$$

Equation (1) is based on the assumption that the flow is stable, unstable, and the flow and uniform velocity profiles occur at the pressure site. However, to account for real fluid effects such as viscosity and compressibility to the empirical coefficients $\mathrm{C}_{\mathrm{d}}$ and $\varepsilon$ are introduced in the equation.

The fluid flow rate, $\mathrm{Q}_{\mathrm{m}}$ is proportional to the square root of the pressure drop. This relationship is the basis of flow measurement using a venturi classic with the following equation:

$$
\mathrm{Q}_{\mathrm{m}} \infty \sqrt{\Delta \mathrm{P}}
$$

This relationship is called bernoulli's formula. Zhi-Yao and Tao using a bernoulli's formula, the flow rate of a singlephase fluid mass is proportional to the square root of the differential pressure in venturi according to the equation (3) (mass flow rate in meters venturi Qm) as follows [4], [5]:

$$
\mathrm{Q}_{\mathrm{m}}=\frac{C d}{\sqrt{1-\beta^{4}}} \varepsilon \frac{\pi \mathbb{d}^{2}}{4} \sqrt{2\left(\frac{p_{1}-p_{2}}{\rho_{1}}\right)}
$$

Where $\mathrm{Qm}$ is the mass flow rate, $\mathrm{Cd}$ is the discharge coefficient, $\beta$ is the beta ratio $(\mathrm{d} / \mathrm{D}), \varepsilon$ is expansion factor $(\varepsilon=$ 1 , for flows that cannot be compressed), $\mathrm{d}$ is the neck diameter of the venturi meter, $\mathrm{D}$ is the upstream pipe which converges venturi, $\mathrm{P} 1$ is static pressure on the upstream pressure, $\mathrm{P} 2$ is static pressure on the venturi neck, $\rho$ is the density of the liquid on the upstream location [4], [5]. The discharge coefficient $(\mathrm{Cd})$ is a ratio of actual flow with the theoretical flow. The purpose of this study is to introduce the effect of the discharge coefficient $(\mathrm{Cd})$ on fluid flow measurements using a venturi tube. However, to account for real fluid effects such as viscosity and compressibility to the empirical coefficients (Cd) and $\varepsilon$ are introduced in the equation [6]. The discharge coefficient of the orifice plate $(\mathrm{Cd})$ is applied to theoretical flow equations to obtain actual flow. The discharge coefficient, otherwise known as the venturi meter coefficient, usually has a value between 0.92 and 0.99 . Therefore, almost $60 \%$ more flow can be obtained through these elements for the same differential pressure [4] - [7].

Perumal Kumar [8] proposed that the effect of venturi convergent and divergent angles using were investigated in ANSYS Fluent by-passing wet gas as a liquid in the horizontal pipe. Experimental results on various ranges of convergent and divergent angles are evaluated. The design models they have used are Steven and DE Leeuw for the venturi design which will give them better results [8]. In Conclusion, they have found out the divergent section having an angle of 15 degrees has higher sensitivity in comparison with the other range of angles in the same. For the convergent section having an angle of 10.5 degrees with the divergent angle of 15 degrees is suitable for wet gas metering using venturimeter in comparison with the orifice meter [8].

A Tukimin [9] describes the drop in pressure and the velocity at the discharge nozzle were analyzed using computational fluid dynamics (CFD) for the determination of better coefficient of discharge (Cd). In this paper, average values for the cd using experimental and numerical analysis is shown using dry gas as a liquid. In conclusion, compared the results of computational fluid dynamics (CFD) and experiments performed in the laboratory to have better results for the coefficient of discharge [9].

Ahmet Baylar [10] analyzed the effect of pressure and velocity variation by changing the diameters of convergent and throat section. In this experiment, holes are bored on the convergent and throat section. With this addition, it is possible to avoid the effect of cavitation. CFD modelling was used to analyze the air injection rate of venture tubes [10]. FLUENT CFD program has been used to measure air injection rates and computed values. The optimum dimension of venturi is proposed to be determined using CFD FLUENT 6.2 program to obtain air injection at a high rate. The region of non-aerated flow length has a co-relation with the diameters of throat [10].

\section{GEOMETRY AND MESHING}

Venturi design is a process with iterations to formalize final geometry model. In this study, the iteration is done with the convergent and divergent angles of venturi to get expected design. Geometry for three different convergent and divergent angles was done in CREO 3.0. With measuring the sections, defined geometry parameters are modelled in CREO 3.0 including convergent angles $(\theta)$, divergent angles $(\varnothing)$ and throat diameter (d). The pipe diameters for a given venturi model kept $40 \mathrm{~mm}$ for both inlet and outlet section. The throat portion is $24 \mathrm{~mm}$ in given models for venturi design. The total length of venturi including convergent and divergent is $135 \mathrm{~mm}$. Here, ANSYS Workbench 14.0 is utilized for the computational fluid dynamics (CFD) approach. Using this approach, sizing of mesh for all models has been selected as a fine structure and having 74448 nodes with 70950 elements.

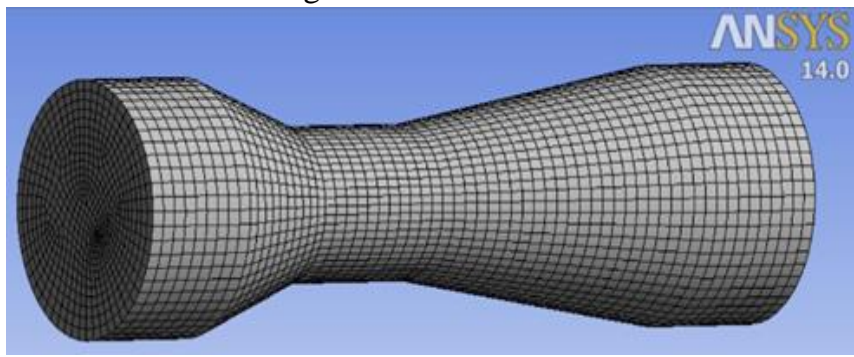

Fig. 2. Meshed modelling of venturi geometry type 1 


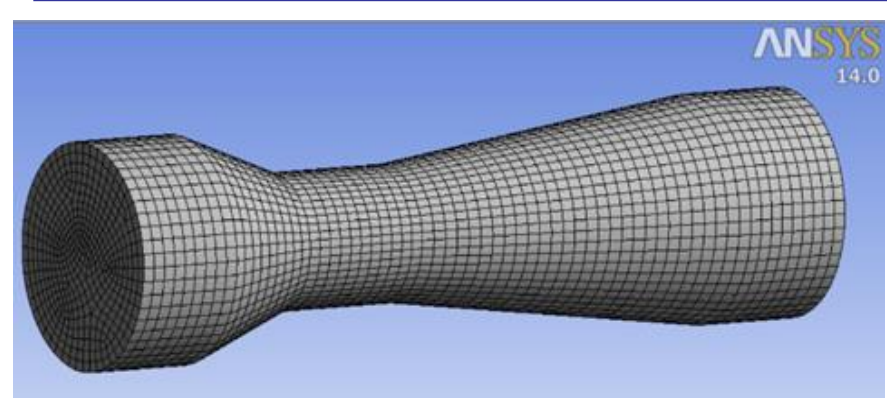

Fig. 3. Meshed modelling of venturi geometry type 2

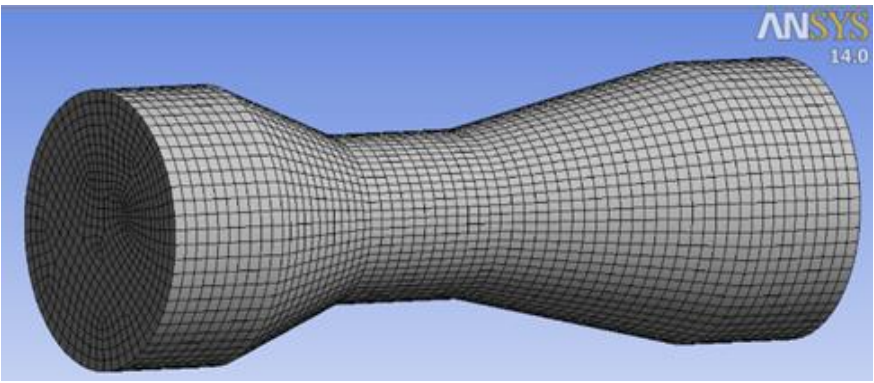

Fig. 4. Meshed modelling of venturi geometry type 3

\section{BOUNDARY CONDITIONS AND ANALYSIS}

In the current study, the venturimeter design files were imported in fluid flow (CFX) tool. At the inlet section, the value defined for static pressure is $57635.71 \mathrm{~Pa}$ and mass flow rate of $0.473 \mathrm{~kg} / \mathrm{s}$.

\begin{tabular}{|l|l|}
\hline \multicolumn{2}{|c|}{ BABLE I: BOUNDARY ENTITIES (CFX SOLVER) } \\
\hline \multicolumn{2}{|c|}{ Properties } \\
\hline Location & Zero Gradient \\
\hline \multicolumn{2}{|c|}{ Properties } \\
\hline Flow Direction & Subsonic \\
\hline Flow Regime & Static pressure \\
\hline Mass and Momentum & S.3645 x 10 \\
\hline Relative Pressure (Pa) & Medium Intensity and Eddy \\
\hline Turbulence & Viscosity Ratio \\
\hline \multicolumn{2}{|c|}{ Boundary - Outlet } \\
\hline Location & Mass Flow Rate \\
\hline \multicolumn{2}{|c|}{ Properties } \\
\hline Flow Regime & D.2000 $10^{-1}$ \\
\hline Mass and Momentum & No slip wall \\
\hline Mass Flow Rate (kg s $\left.{ }^{-1}\right)$ & Smooth wall \\
\hline \multicolumn{2}{|c|}{ Boundary - Wall } \\
\hline Location
\end{tabular}

No slip wall condition for the mass and momentum considering wall roughness as a smooth. The fluid flow considered for the experimental analysis is carried with water as a fluid medium.

\section{RESULTS AND DISCUSSION}

The experimental investigation has been carried out on the setup facility for venturimeter designs as discussed in the section of experimental procedure. This set up comprises of two pipelines of $40 \mathrm{~mm}$ and $25 \mathrm{~mm}$ diameter placed in parallel and fixed to the mild steel (M.S) stand. Each pipe has individual venturimeter and orifice meter with pressure tapings. Both venturi and orifice meter are fitted in the piping system with sufficiently long pipe lengths upstream of the meters. The pressure tapings are connected to a common middle chamber as well as the $\mathrm{U}$ tube differential manometer. The liquid used in the manometer was mercury (specific gravity $(\mathrm{Sw})=13.6)$. To control the flow through both pipeline flow control valve has been placed at the inlet and outlet of a pipeline. In this setup, the pipeline of $40 \mathrm{~mm}$ diameter was used to perform the experiments. According to that, the venturi installed on the same pipeline. By opening and closing the flow control valve which gives the manometric reading using $U$ tube differential manometer. The water was collected in the water collection tank for the 100 $\mathrm{mm}$ rise of water level in the corresponding tank.

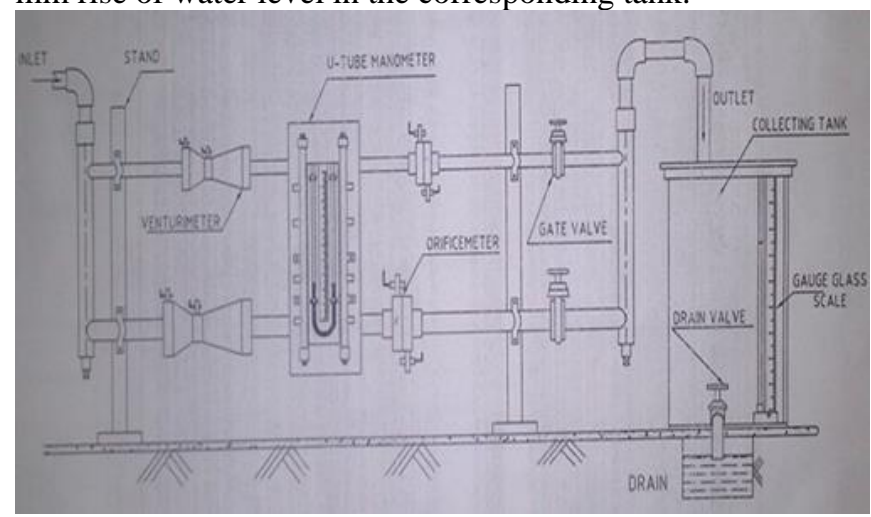

Fig. 5. Experimental Setup

The area of pressurized water collection tank was $0.036 \mathrm{~m} 2$. The flow rate for fluid flow is varied as per procedures followed. The fluid flow for the experimental setup controlled through the flow control valve.

The reading values were taken at atmospheric pressure of 1 Kpa and temperature of 30 degrees by keeping the specific gravity of water and mercury as a standard. The drop in pressure head $(\mathrm{m})$ calculated by adding the $\mathrm{U}$ tube differential manometer $(\mathrm{H} 1, \mathrm{H} 2)$ located at the convergent and throat section. To calculate the coefficient of discharge $\left(C_{d}\right)$ value of theoretical and actual flow rate has been studied at the 100 $\mathrm{mm}$ rise of water level. 


\begin{tabular}{|c|c|c|c|c|c|c|c|c|}
\hline \multirow{2}{*}{$\begin{array}{l}\text { Geometry } \\
\text { type }\end{array}$} & \multicolumn{2}{|c|}{ Venturi Angles ( ${ }^{\circ}$ ) } & \multicolumn{2}{|c|}{$\begin{array}{l}\text { Manometer } \\
\text { Reading } \\
\text { (m) }\end{array}$} & \multirow{2}{*}{$\begin{array}{c}\begin{array}{c}\text { Pressure } \\
\text { Drop (m) }\end{array} \\
h=12.6 \\
(H 1-H 2)\end{array}$} & \multirow{2}{*}{$\begin{array}{c}\begin{array}{c}\text { Actual Flow } \\
\text { rate }\left(Q_{\mathrm{a}}\right) \\
\left(\mathrm{m}^{3} / \mathrm{s}\right)\end{array} \\
Q_{a=0.036 / t}\end{array}$} & \multirow{2}{*}{$\begin{array}{c}\begin{array}{c}\text { Theoretical flow } \\
\text { rate }\left(\mathbf{Q}_{t}\right) \\
\left(\mathbf{m}^{3} / \mathbf{s}\right)\end{array} \\
Q_{t}=0.002148(h)^{0.5}\end{array}$} & \multirow{2}{*}{$\begin{array}{c}\begin{array}{c}\text { Coefficient } \\
\text { of Discharge } \\
\left(\mathbf{C}_{\mathrm{d}}\right)\end{array} \\
C_{d}=Q_{d} / Q_{t}\end{array}$} \\
\hline & $\begin{array}{c}\text { Convergent } \\
\left(\theta_{c}\right)\end{array}$ & $\begin{array}{c}\text { Divergent } \\
\left(\emptyset_{d}\right)\end{array}$ & H1 & $\mathrm{H}_{2}$ & & & & \\
\hline \multirow{4}{*}{1} & \multirow{4}{*}{21} & \multirow{4}{*}{9} & 0.437 & 0.427 & 0.1260 & $6.79 \times 10^{-4}$ & $7.62 \times 10^{-4}$ & 0.89 \\
\hline & & & 0.435 & 0.426 & 0.1134 & $7.05 \times 10^{-4}$ & $7.23 \times 10^{-4}$ & 0.97 \\
\hline & & & 0.434 & 0.425 & 0.1134 & $7.20 \times 10^{-4}$ & $7.23 \times 10^{-4}$ & 0.99 \\
\hline & & & 0.434 & 0.423 & 0.1386 & $7.20 \times 10^{-4}$ & $7.99 \times 10^{-4}$ & 0.99 \\
\hline \multirow{4}{*}{2} & \multirow{4}{*}{20} & \multirow{4}{*}{11} & 0.436 & 0.426 & 0.1260 & $7.05 \times 10^{-4}$ & $7.62 \times 10^{-4}$ & 0.92 \\
\hline & & & 0.435 & 0.425 & 0.1260 & $6.92 \times 10^{-4}$ & $7.62 \times 10^{-4}$ & 0.90 \\
\hline & & & 0.434 & 0.424 & 0.1260 & $7.05 \times 10^{-4}$ & $7.62 \times 10^{-4}$ & 0.92 \\
\hline & & & 0.435 & 0.426 & 0.1134 & $6.42 \times 10^{-4}$ & $7.23 \times 10^{-4}$ & 0.88 \\
\hline \multirow{4}{*}{3} & \multirow{4}{*}{21} & \multirow{4}{*}{7} & 0.434 & 0.424 & 0.1260 & $7.50 \times 10^{-4}$ & $7.62 \times 10^{-4}$ & 0.98 \\
\hline & & & 0.435 & 0.426 & 0.1134 & $6.92 \times 10^{-4}$ & $7.23 \times 10^{-4}$ & 0.95 \\
\hline & & & 0.434 & 0.425 & 0.1134 & $6.42 \times 10^{-4}$ & $7.23 \times 10^{-4}$ & 0.88 \\
\hline & & & 0.430 & 0.42 & 0.1260 & $6.31 \times 10^{-4}$ & $7.62 \times 10^{-4}$ & 0.82 \\
\hline
\end{tabular}

\section{A. Geometry type: 1}

The analysis of venturi sections based on computational fluid dynamics (CFD) has been conducted as shown below. The following results for the pressure and velocity contours are analyzed and represented according to the geometry of venturi having convergent and divergent angles as $\theta \mathrm{c}=21$, $\varnothing_{\mathrm{d}}=9$.

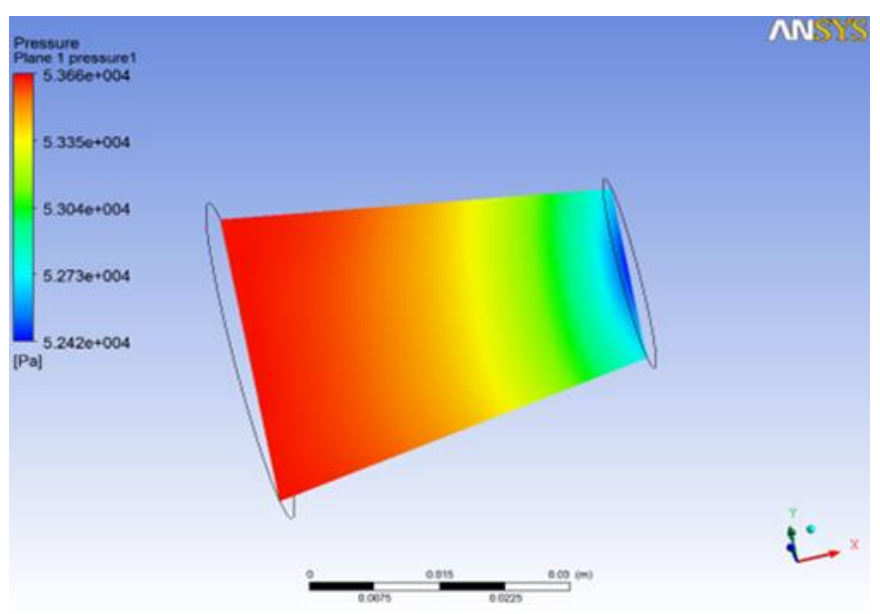

Fig. 6. Pressure variation for venturi model $\left(\theta_{c}=21, \varnothing_{d}=9\right)$

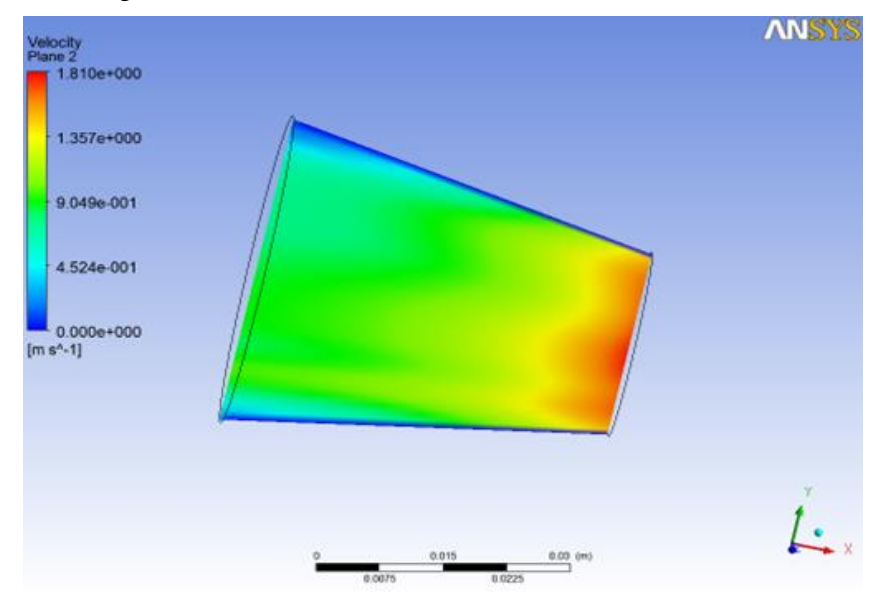

Fig. 7. Velocity variation for venturi model $\left(\theta_{c}=21, \varnothing_{d}=9\right)$

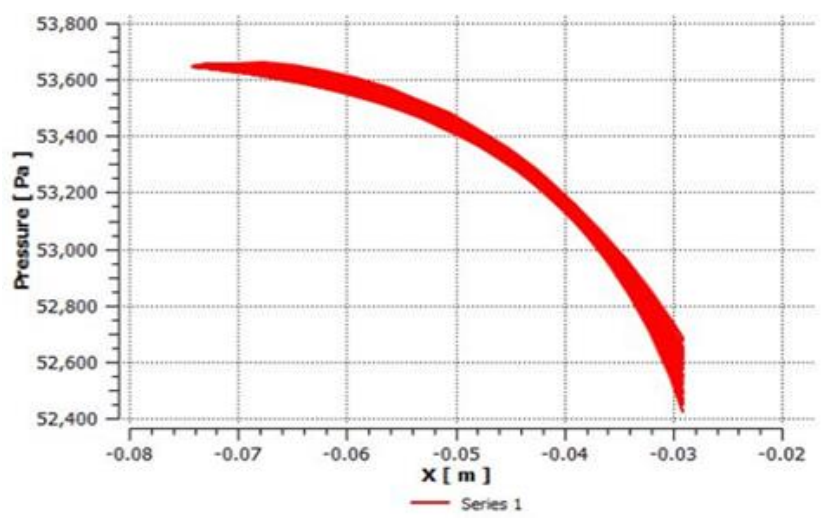

Fig. 9. Velocity variation plot for convergent section $\left(\theta c=21, \varnothing_{d}=9\right)$

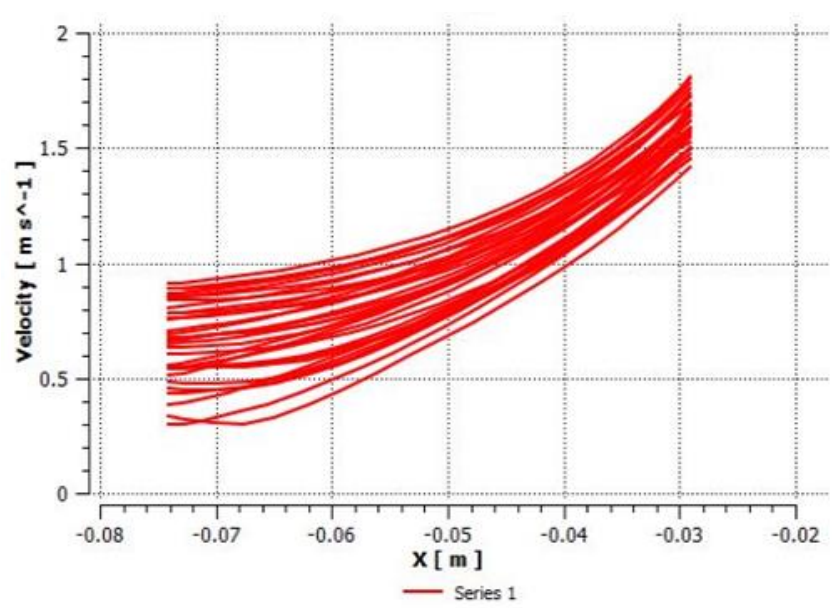

Fig. 8. Pressure variation plot for convergent section $\left(\theta_{c}=21, \emptyset_{d}=9\right)$ 
The convergent section is evaluated for pressure and velocity variation across $\mathrm{X}$-direction with pressure and velocity vector. It concludes that there is a considerable drop in pressure at the convergent section from $53660.35 \mathrm{~Pa}$ to $52420.15 \mathrm{~Pa}$ as shown in Fig. 6 and Fig. 8. The velocity variation from 0 to $1.810 \mathrm{~m} / \mathrm{s}$ (inlet to throat) as shown in Fig. 7 and Fig. 9, due to change in the cross-section at the convergent portion. Here 25 iterations were taken for pressure and velocity variation.

\section{B. Geometry type: 2}

For the next set of geometric models having convergent angle $(\theta c)=20$, divergent angle $\left(\varnothing_{\mathrm{d}}\right)=11$ has been analyzed in CFX solver for computational fluid dynamics (CFD) computation. The variation provided in the second geometry configuration gives out another pressure and velocity variation across $\mathrm{X}$-direction. As the variation in convergent and divergent angles impact the results plotted in Fig. 10 and Fig. 12. Variation in pressure is seen gradual, attains value from $53770.05 \mathrm{~Pa}$ to $52560.25 \mathrm{~Pa}$. Fig. 11 and Fig. 13 shows velocity variation for the venturi having convergent angle $(\theta \mathrm{c})=20$ and divergent angle $\left(\varnothing_{\mathrm{d}}\right)=11$. Velocity streamline represents the variation in velocity from 0 to $1.888 \mathrm{~m} / \mathrm{s}$.

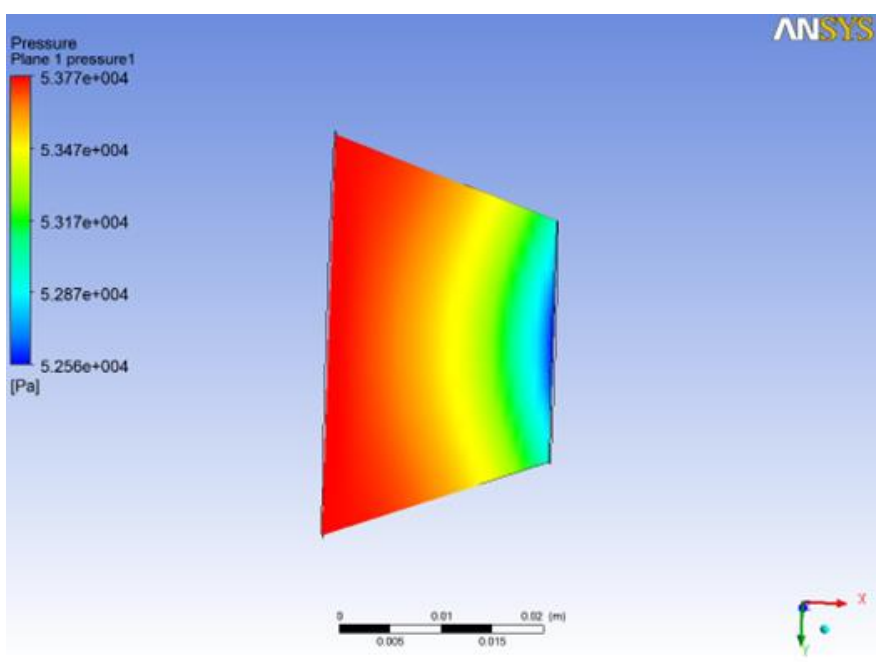

Fig. 10. Pressure variation for venturi model $\left(\theta_{\mathrm{c}}=20, \varnothing_{\mathrm{d}}=11\right)$

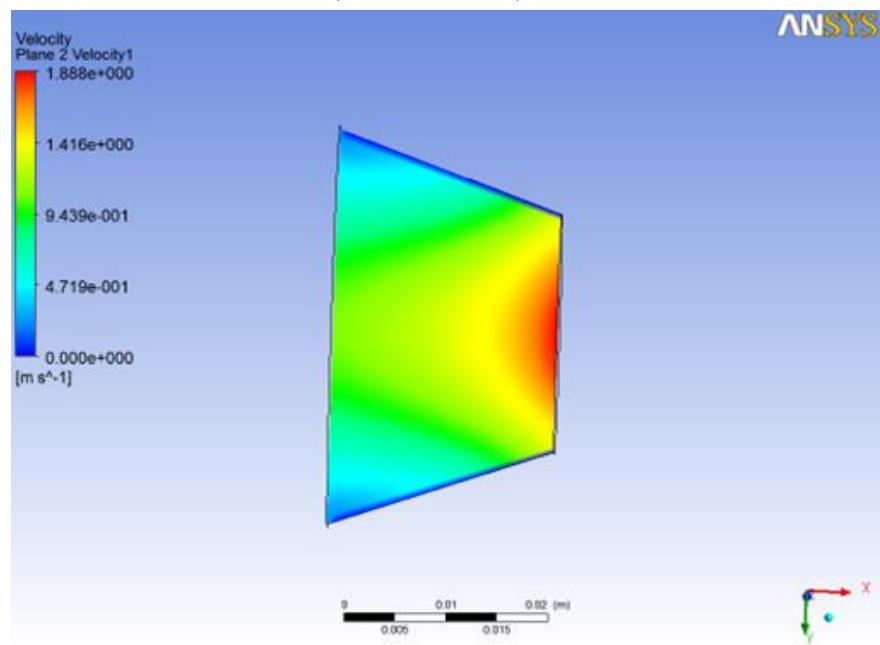

Fig. 11. Velocity variation for venturi model $(\theta c=20, \emptyset d=11)$

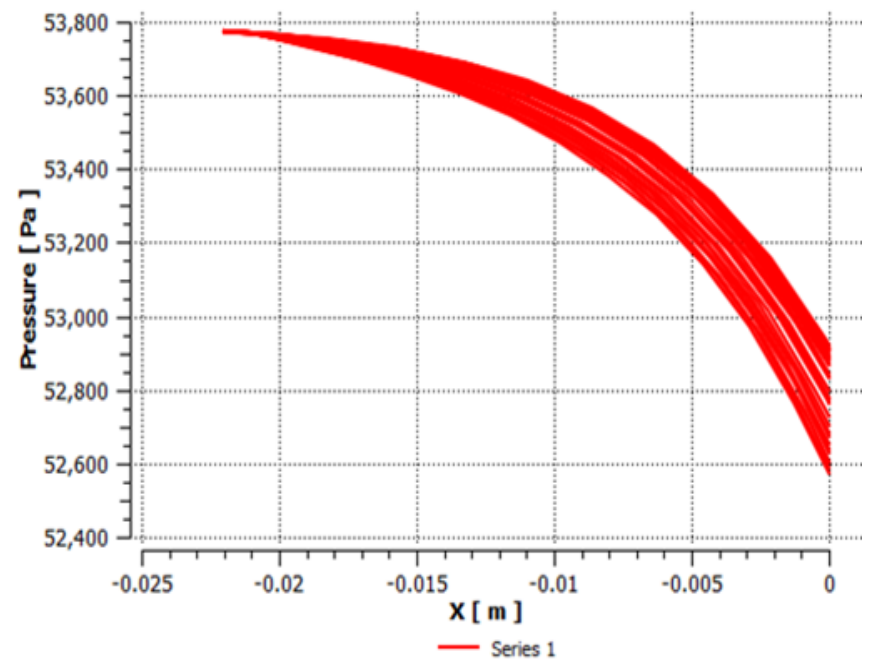

Fig. 12. Pressure variation plot for convergent section $\left(\theta \mathrm{c}=20, \varnothing_{\mathrm{d}}=11\right)$

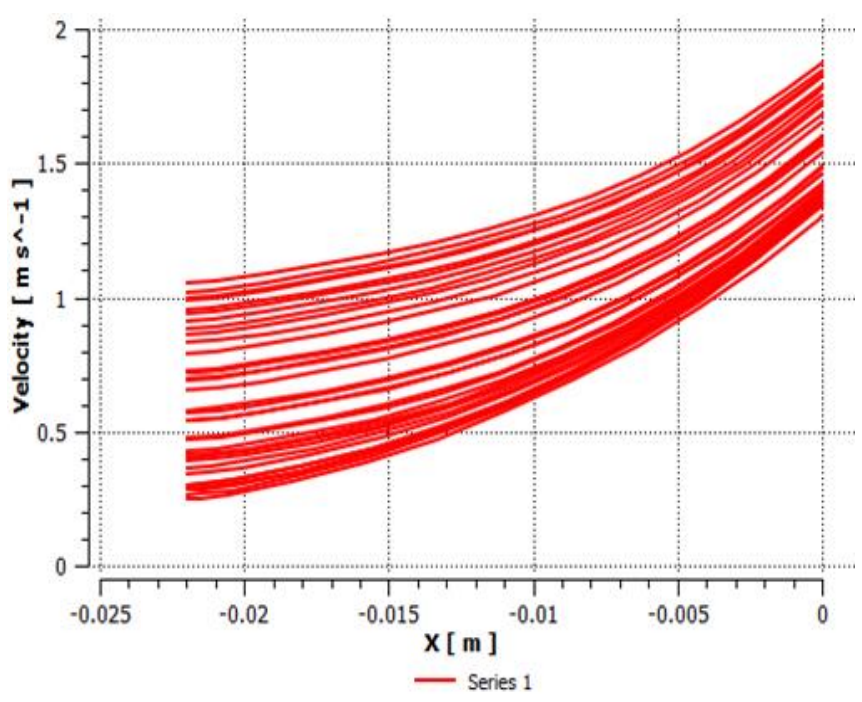

Fig. 13. Velocity variation plot for convergent section $\left(\theta \mathrm{c}=20, \varnothing_{\mathrm{d}}=11\right)$

\section{Geometry type: 3}

In the third set of geometric models having angle $\theta_{c}=20$, $\emptyset_{\mathrm{d}}=11$ has been utilized to perform computational fluid dynamic (CFD). The drop in pressure from 53660.54 Pa to $52420 \mathrm{~Pa}$ at the inlet section of venturi along the $\mathrm{X}$ direction is as shown in Fig. 14 and Fig. 16. Velocity variation is shown in Fig. 15 and Fig. 17 with the contours varies from 0 to $1.810 \mathrm{~m} / \mathrm{s}$. 


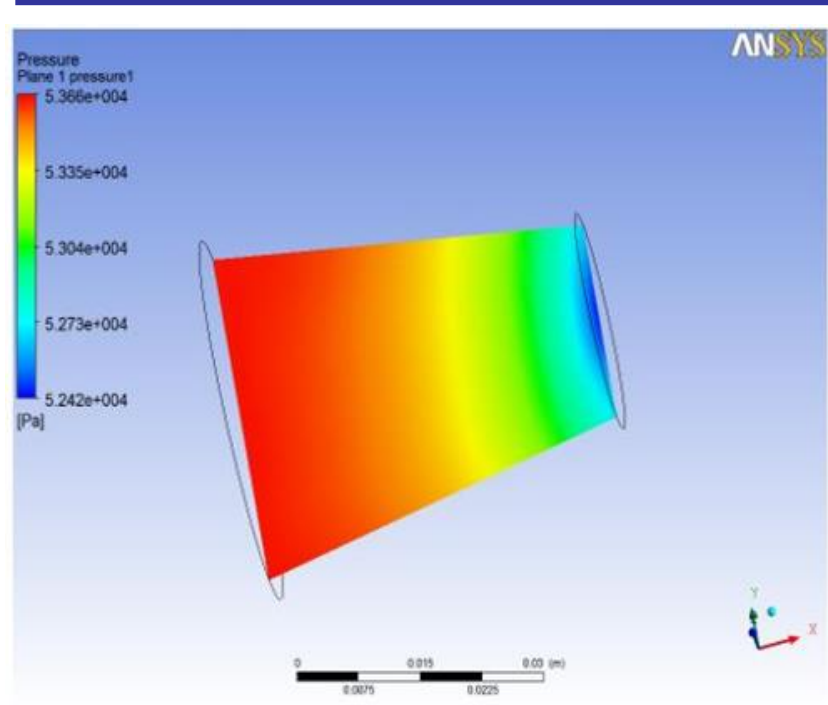

Fig. 14. Pressure variation for venturi model $\left(\theta_{\mathrm{c}}=21, \varnothing_{\mathrm{d}}=7\right)$

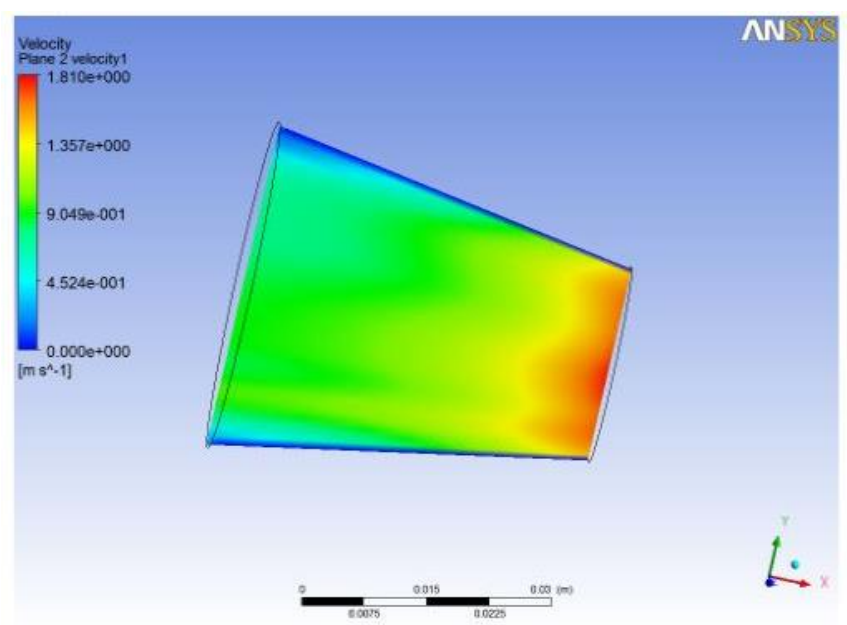

Fig. 15. Velocity variation for venturi model $\left(\theta_{\mathrm{c}}=21, \varnothing_{\mathrm{d}}=7\right)$

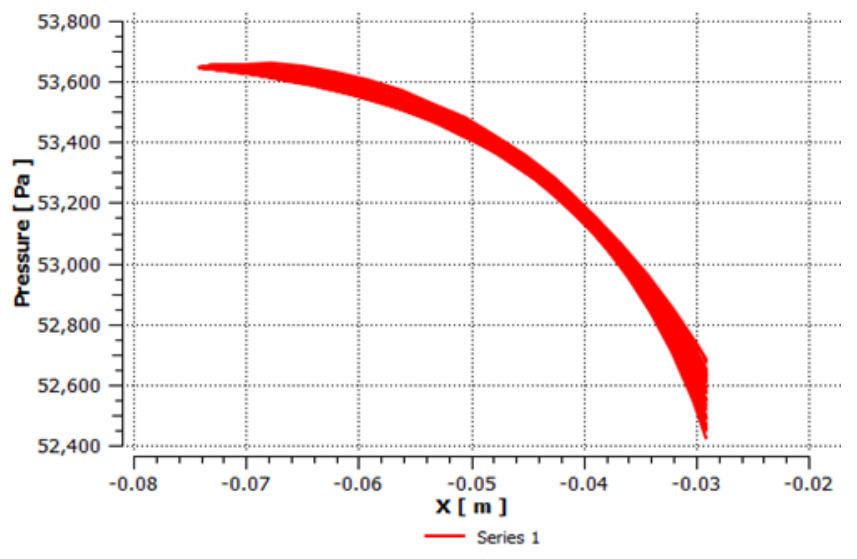

Fig. 16. Pressure variation plot for convergent section

$$
\left(\theta_{\mathrm{c}}=21, \varnothing_{\mathrm{d}}=7\right)
$$

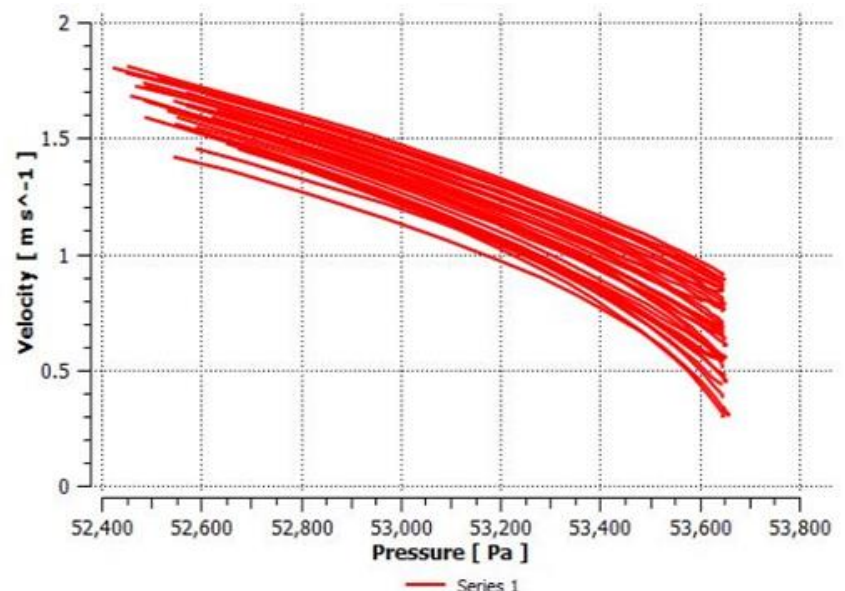

Fig. 17. Velocity variation for venturi model $\left(\theta c=21, \varnothing_{d}=7\right)$

Above performed analysis with computational fluid dynamics has been carried out with the three different geometric models having different convergent and divergent angles as shown from Fig. 2 to Fig. 4. Respective changes across the pressure and velocity distribution have been studied and evaluated for fluid dynamics modelling and simulation tools including CFX solver, PTC CREO 3.0, ANSYS Workbench 14.0.

\section{Evaluation of discharge coefficient (Cd) using experimental and CFD analysis method}

- Theoretical discharge for venturimeter (Numerical computation)

Difference in manometer level $=\mathrm{x}$ in $\mathrm{m}$. of $\mathrm{Hg}$ Equivalent pressure drops $(\mathrm{h})=\mathrm{x}(13.6-1) \mathrm{m}$. of water $\mathrm{h}=12.6 \mathrm{x} \mathrm{m}$ of water.

Qth $=(0.002148 \sqrt{ } \mathrm{h})$ for $40 \mathrm{~mm}$ pipeline.

- Actual discharge for venturimeter (Lab setup)

The area of collecting tank,

$\mathrm{A}=0.6 \times 0.6 \mathrm{~m} 2$.

Rise $(\mathrm{R})=0.1 \mathrm{~m}$

Time taken $=\mathrm{t}$ sec.

The actual discharge,

$\mathrm{Qa}=\mathrm{A} . \mathrm{R} / \mathrm{t}$

Coefficient of discharge $(\mathrm{Cd})=\mathrm{Qa} /$ Qth

Where,

$\mathrm{Qa}=$ Actual discharge for venturimeter

$\mathrm{Qth}=$ Theoretical discharge for venturimeter

$\mathrm{h}=$ Rise of water level in collecting tank

$\mathrm{x}=$ Difference of pressure in manometer of fluid

The value of discharge coefficient $\left(\mathrm{C}_{\mathrm{d}}\right)$ calculated using numerical computation through a set of equations for venturimeter. Further calculations are carried out for the different set of convergent angles $\left(\theta_{c}\right)$ and divergent angle $\left(\varnothing_{\mathrm{d}}\right)$. 
TABLE III: COMPARISON OF EXPERIMENTAL AND CFD ANALYSIS

\begin{tabular}{|c|c|c|c|c|c|}
\hline \multirow{2}{*}{ Type } & \multicolumn{2}{|c|}{$\begin{array}{c}\text { Venturi } \\
\text { Angles }\end{array}$} & \multicolumn{2}{c|}{ Coefficient of discharge $\left(\mathrm{C}_{\mathrm{d}}\right)$} & \multirow{2}{*}{$\begin{array}{c}\text { Change } \\
(\%)\end{array}$} \\
\cline { 2 - 5 } & $\theta_{\mathrm{c}}$ & $\varnothing_{\mathrm{d}}$ & $\begin{array}{c}\text { Experimental } \\
\text { Method }\end{array}$ & CFD analysis & \\
\hline 1. & 21 & 9 & 0.9983 & 0.9443 & 5.40 \\
\hline 2. & 20 & 11 & 0.9079 & 0.8283 & 8.71 \\
\hline 3. & 21 & 7 & 0.8283 & 0.8887 & 6.80 \\
\hline
\end{tabular}

The above table shows the change in value of discharge coefficient $(\mathrm{Cd})$ for experimental method and CFD analysis.

\section{CONCLUSION}

In this study, different geometries of venturimeter models are analyzed and compared with the experimental fluid lab setup results. Overall calculation and simulations are performed for the study of convergent $\left(\theta_{c}\right)$ and divergent angles $\left(\varnothing_{\mathrm{d}}\right)$ of venturi and their impact on the coefficient of discharge $\left(\mathrm{C}_{\mathrm{d}}\right)$. The experimented procedure includes performing different simulations through computational fluid dynamics (CFD) approach, pressure distribution and velocity distributions are examined in the form of contour plots.

The venturi having beta ratio $(\beta)=0.6$, convergent angle $\left(\theta_{c}\right)=21$ and divergent angle $\left(\varnothing_{d}\right)=9$ result with $5 \%$ of variation in the coefficient of discharge $\left(\mathrm{C}_{\mathrm{d}}\right)$. Whereas the $\left(\theta_{c}\right)=20$ and divergent angle $\left(\varnothing_{d}\right)=11$ produced variable results in accordance with the value of coefficient of discharge $\left(\mathrm{C}_{\mathrm{d}}\right)$. Here, the method including experimental as well as computational fluid dynamics (CFD) based proved that the second geometry model of venturimeter has moderate feasibility as compared to the model shown with approximately $5 \%$ change in the coefficient of discharge $\left(\mathrm{C}_{\mathrm{d}}\right)$.

Based on various industrial applications of venturi, parameters such as material, mass flow rate, actual flow rate and drop in pressure etc. which plays an important role to reduce the change in percentage of coefficient of discharge $\left(\mathrm{C}_{\mathrm{d}}\right)$.

\section{REFERENCES}

[1] Arun R, (2015). "Prediction of discharge coefficient of venturimeter at low reynolds numbers by analytical and cfd method" published in International Journal of Engineering and Technical Research (IJETR) ISSN: 2321-0869, Volume-3, Issue-5, May 2015.

[2] M. D. Bassett, D. E. Winterbone, R. J. Pearson, (2001). "Calculation of steady flow pressure loss coefficients for pipe junctions", Journal of Mechanical Engineering Science, vol., 215, no. 8, pp. 861-881, 2001.

[3] Boyes, W. H. (2001). "Pumps and flowmeters hand in hand." Flow Control

[4] Zhi-yao, Z.-j.Y.W.-t.H. (2005). "Investigation of oil-air two-phase mass flow rate measurement using venturi and void fraction sensor", Journal of Zhejiang University Science, 6A (6), 601- 606.

[5] Tao, F.L.Z. (2008). "Performance of a horizontally mounted venturi in low pressure wet gas flow", Chinese Journal of Chemical Engineering, 16(2), 320-324.

[6] T. Nithin, Nikhil Jain and Adarsha Hiriyannaiah (2012). "Optimization of venturi flow meter model for the angle of divergence with minimal pressure drop by computational fluid dynamics method", International Conference on Challenges and Opportunities in Mechanical Engineering, Industrial Engineering and Management Studies.

[7] Hutagalung, Sutrisno Salomo. (2019). "Estimation optimal value of discharge coefficient in a venturi tube." In Journal of Physics: Conference Series, vol. 1230, no. 1, p. 012087. IOP Publishing, 2019.

[8] Perumal Kumar and Sim Mei San (2014). "CFD study of the effect of venture convergent and divergent angles on low pressure wet gas metering”, Journal of applied sciences 14(22): 3036-3045, ISSN 1812-5654.

[9] A Tukimin, M Zuber and K A Ahmad (2016). "CFD analysis of flow through venturi tube and it is discharge coefficient", IOP Conf. Series: Materials Science and Engineering 152, 2062 doi:10.1088/1757-899X/152/1/012062

[10] Ahmet Baylar, M. Cihan Aydin, Mehmet Unsal and Fahri Ozkan (2009). "Numerical modelling of venturi flows for determining air injection rates using fluent v6.2", Mathematical and Computational applications, Vol.14, No.2, pp 97-108, 2009.

[11] Bansal, R. K. A textbook of (2004). "Fluid mechanics and hydraulic machines" Laxmi publications, 2004. 